scientists who are fond of history. They will particularly enjoy the chapter on the creation of the metric system, the narrative on Condorcet's death, the subtle analysis of the Monge connection, and, above all, Napoleon's fascinating and exotic expedition to Egypt.

Bruno Belhoste and Bernadette Bensaude-Vincent are professors of the history of science,

Université Paris X, 200 Avenue de la république,

92001 Nanterre, France.

\section{A brain in the hand}

\section{On Intelligence: How A New Understanding of The Brain Will Lead to the Creation of Truly Intelligent Machines \\ Jeff Hawkins, with Sandra Blakeslee \\ Times Books: 2004. 272 pp. \$25}

\section{Igor Aleksander}

With so many books published recently on minds, machines and intelligence, it is becoming progressively more difficult to find their distinguishing features. Happily, Jeff Hawkins has a unique perspective, as one of the pioneers of hand-held electronic organizers and founder of the Palm Computing and Handspring companies, whose products adorn the pockets of executives and technical boffins alike. His hard-nosed grasp of complex digital-system design and his passion for neuroscience are the authoritative bases for this book.

On Intelligence may not herald a future of super-intelligent hand-held computers, but it does analyse how this objective could be approached from an understanding of some particular and complex computational features of the brain. It is written as a personal history, with step one for Hawkins being the realization in the mid-1980s that computers and research into artificial intelligence had not produced the kind of intelligence that each and every one of us possesses. He has always felt that artificial intelligence, being based on achieving smart outward behaviour through the speed and power of a computer, tells us nothing about what intelligence is, and why brains are better at it than computers. He argues that the brain can be understood only if its intricate architecture can be analysed and turned into computing theories. His ideas were rejected by both industry and the academic world at a time when the stranglehold of the 'power and speed' approaches of the 'artificial intelligentsia' did not recognize the power of brain models, caricaturing the brain as 'slow and squishy'. Well into his career as a successful computer engineer, Hawkins studied biology and neurology at night and then gave up his day job to become a graduate student in biophysics at the University of California, Berkeley.

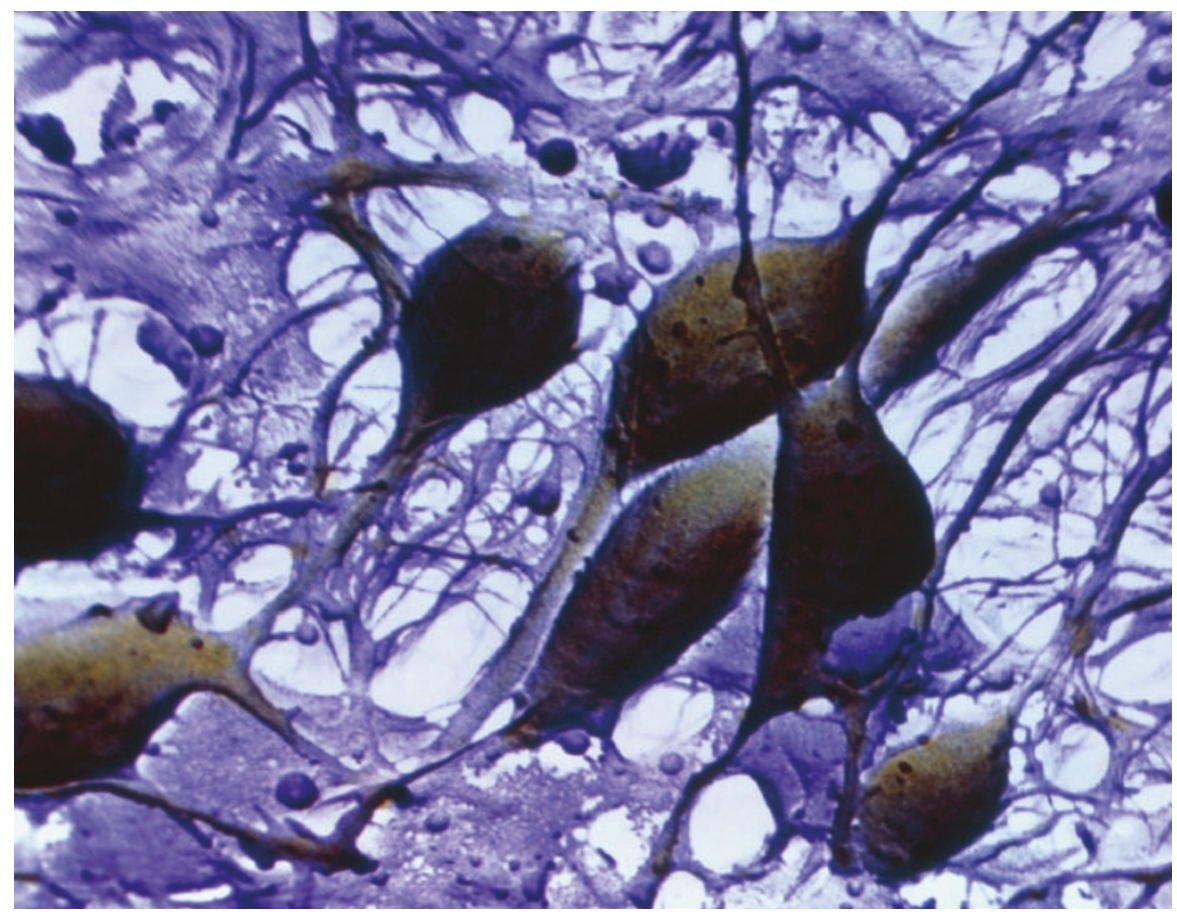

Smart thinking: understanding the cerebral cortex can aid the development of intelligent computers.

Hawkins made the move just as neural networks, or connectionism, became the favoured alternative to classical artificial intelligence. But this too proved to be a disappointment. Neural networks were only distantly inspired by the brain and this remoteness was fatal. Connectionism became obsessed with the mathematics of learning and revealed little about the nature of real intelligence. The brain, as the most complex machine on the planet, remained unexplored in the computational sense.

Depressed by these failures and the seeming flood of uncoordinated data that neuroscience produces, Hawkins started looking for organizing principles. He turned to the work of Vernon Mountcastle of Johns Hopkins University in Baltimore, who advocates looking for common mechanisms in different modalities. Although vision and hearing are different, for example, the ways in which signals are processed in the two cases bear an engineering similarity that points to general principles underlying both.

Much of On Intelligence could be summed up as 'how computer scientists got it wrong. Memory in the brain is an active affair that stems from the interaction of cells. It has stable states that provide the 'Aha!' sensation when an input trigger causes part of the brain to fall into such a state. This is a long way from the filing-cabinet type of memory in conventional computers. The brain is constantly trying to predict its input, whereas a computer merely waits for the input and reacts to it. These differences lead to clear expositions by Hawkins of the way the cortex may be organized to achieve this active engagement with the world, which is true intelligence. The working of the cortex leads Hawkins to comment on the fallacy of treating consciousness "like a sauce" that turns meat into a conscious being; instead he makes a series of testable predictions about the power of his memory-prediction model.

Anyone looking for a blueprint for the ultimate conscious, palm-held computer will be disappointed. This is not a book on how to compute, it's more about how not to compute. The book is clear and punchy, and is fine for general reading, thanks in some measure to Hawkins' co-author, Sandra Blakeslee, a columnist at The New York Times who has helped several authors improve their books about mind and psychology. As with other computational experts who have written about the mind, Hawkins could be criticized for not having noticed that many computer scientists share his views. The time has come for people who share these ideas to stop deprecating previous efforts and look at each other's work. Other authors have suggested architectures like those proposed by Mountcastle (without mentioning him), for example, and analyses of dynamic memories and prediction have been appearing in the literature since the mid-1990s.

Nevertheless, Hawkins makes an appealing case for the sort of computational analysis that is likely both to clarify how the brain works and to give artificial-intelligence systems a new grounding. Such work requires more collaboration among those who agree with Hawkins. The fact that two years ago he created the Redwood Neuroscience Institute should help.

Igor Aleksander is emeritus professor of neural systems engineering at Imperial College London, Exhibition Road, London SW7 2BT, UK. His book The World In My Mind will be published in 2005. 